\title{
Potential of Carboxymethylated Polyallylamine as a Functional Group on Chelating Resin for Solid-Phase Extraction of Trace Elements
}

\author{
Shigehiro Kagaya, ${ }^{*}$ Yumi SaekI,* Daiki Morishima,* Takehiro KaJIWara,* Waka KaMichatani, ** \\ Hideyuki YanaI, ${ }^{* *}$ Toshifumi KatoH, $* *$ Mitsuru SaIto, $* *$ Makoto GemmeI-Ide, $*$ and \\ Yoshinori INOUE*
}

*Faculty of Engineering, University of Toyama, Toyama 930-8555, Japan

**Research and Development Center, Nippon Filcon Co., Ltd., Inagi, Tokyo 206-8577, Japan

\begin{abstract}
New chelating resins immobilizing carboxymethylated polyallylamine (CM-PAA) were prepared by immobilizing PAAs with some molecular weights on methacrylate resins and then carboxymethylating a part of amino groups in the PAAs using various amounts of sodium monochloroacetate. The molecular weight of PAA barely affected both the amount of PAA immobilized on the resin and the relationship between the carboxymethylation (CM) rate and the ratio of the amount of monochloroacetate used in the CM step. The selectivity of CM-PAA resin for solid-phase extraction of trace elements was almost the same as that of a resin immobilizing carboxylymethylated polyethyleneimine; 10 elements, namely Cd, $\mathrm{Co}, \mathrm{Cu}, \mathrm{Fe}, \mathrm{Mo}, \mathrm{Ni}, \mathrm{Pb}, \mathrm{Ti}, \mathrm{V}$, and $\mathrm{Zn}$, could be quantitatively recovered over a wide $\mathrm{pH}$ range and alkali and alkaline earth elements were scarcely extracted under acidic and neutral conditions. The CM-PAA resin was applicable to the separation and preconcentration of the elements in a certified reference material (Waste Water, EU-L-1) and a real environmental water sample (ground water).
\end{abstract}

Keywords Chelating resin immobilizing carboxymethylated polyallylamine, solid-phase extraction, trace element, selectivity, environmental water sample

(Received December 31, 2019; Accepted February 13, 2020; Advance Publication Released Online by J-STAGE February 21, 2020)

\section{Introduction}

Solid-phase extraction using a chelating resin is one of the useful techniques for separation and preconcentration of trace elements. ${ }^{1-4}$ Chelating resins immobilizing various functional groups can be purchased from suppliers. ${ }^{4}$ A chelating resin immobilizing aminocarboxylic acid is widely used because it can extract many elements. ${ }^{5}$ A new generation of the chelating resins immobilizing aminocarboxylic acid, namely NOBIAS Chelate PA-1 (Hitachi High-Tech Fielding), 5-19 InertSep ME-2 (GL Sciences), ${ }^{20}$ and Presep PolyChelate (FUJIFILM Wako Pure Chemical), ${ }^{5,13,21-28}$ has been developed and the application of these resins for solid-phase extraction of trace elements in environmental samples has recently increased. These resins imperceptibly extract alkali and alkaline earth elements, which are sometimes contained at high concentration in various environmental samples and often interfere with the determination of trace elements using atomic spectroscopy, under acidic and neutral conditions..$^{5,20}$

The selectivity of such chelating resins has been studied using chelating resins immobilizing carboxymethylated polyethyleneimine (CM-PEI) with different carboxymethylation (CM) rates; ${ }^{29,30}$ the CM-PEI is the functional group in Presep

† To whom correspondence should be addressed.

E-mail: kagaya@eng.u-toyama.ac.jp
PolyChelate. The resin is prepared by immobilizing PEI to a porous methacrylate resin and then carboxymethylating a part of the amino groups in the PEI on the resin using sodium monochloroacetate (MCA). A balance of aminocarboxylic acid groups and residual amino groups, which are protonated under acidic and neutral conditions, in the CM-PEI on the resin is very important for the selectivity; the former mainly functions to complex with elements and the latter works as the electrorepulsion site to exclude some elements such as alkaline earth elements. ${ }^{29}$ The CM rate is defined as the ratio of the amount of carboxymethyl group to the amount of nitrogen on the resin. Therefore, it is necessary to ensure the same CM rate in order to provide the same selectivity to CM-PEI resin. Many commercially available PEIs generally have a branch structure with primary, secondary, and tertiary amino groups present in the molecule. The ratio is different by manufacturer and it often differs depending on the reagent lot even when the manufacturer is the same. The nucleophilicity of the amino group obeys its reactivity with $\mathrm{MCA}^{31}$ In the case of aliphatic amine, the nucleophilicity generally decreases as follows: secondary $>$ tertiary $>$ primary. ${ }^{31}$ The information indicates that the same $\mathrm{CM}$ rate is not obtained in the carboxymethylation of amino groups in PEIs having different branch structure even when the same amount of MCA is used. It is a serious issue in the control of the quality, especially the selectivity, of the chelating resin immobilizing CM-PEI.

Polyallylamine (PAA) is a regular macromolecule, which 
consists of alkyl backbone and side-chain aminomethyl group as a repeating unit. Aqueous solutions containing PAAs having various molecular weights are commercially available. PAA has only primary amino groups even when the manufacturer and the reagent lot are different. This seems that the control of the CM rate in PAA with the amount of MCA is easier than that in PEI. InertSep ME-2 has an iminodiacetic acid group and tertiary amino group individually on the base resin..$^{20}$ This indicates that selectivity can be supported even when aminocarboxylic acid group and amino group are independently present. This fact suggests the possibility that a chelating resin immobilizing CMPAA can show the selectivity comparable to that for immobilizing CM-PEI.

In this work, the potential of CM-PAA as a functional group on chelating resin for selective solid-phase extraction of trace elements is reported. The preparation conditions, including the immobilization of PAA on a porous methacrylate resin and the carboxymethylation of PAA on the resin, are optimized. The ability of the prepared resins for solid-phase extraction are also evaluated. Additionally, the application to solid-phase extraction of some trace elements in a certified reference material and real environmental water samples is attempted.

\section{Experimental}

\section{Apparatus}

Elemental analysis was conducted using an Elementar varioMICRO cube. Deionized water, which was prepared using Merck Elix-UV3 and Milli-Q Gradient, was used for all the investigations related to solid-phase extraction. For measuring the solution $\mathrm{pH}$, a Horiba D-24 pH meter was utilized. A PerkinElmer Optima 7300DV inductively coupled plasma atomic emission spectrometer (ICP-AES) was used for determining elements; the operating conditions are summarized in Table S1 in Supporting Information.

\section{Reagents}

Aqueous solutions containing polyallylamines (PAAs) having different molecular weights were purchased from Nittobo; PAA01 (molecular weight of $c a$. 1600, concentration of $15.2 \mathrm{w} / \mathrm{w} \%$, density of $1.023 \mathrm{~g} \mathrm{~cm}^{-3}$ ), PAA-03 (ca. 3000, $20.3 \mathrm{w} / \mathrm{w} \%$, $1.035 \mathrm{~g} \mathrm{~cm}^{-3}$ ), and PAA-08 (ca. 8000, $15.3 \mathrm{w} / \mathrm{w} \%, 1.020 \mathrm{~g} \mathrm{~cm}^{-3}$ ) were used in this study. As standard solutions for elements, ICP multi-element standard solution XVI (As, Be, Ca, Cd, Co, Cr, $\mathrm{Cu}, \mathrm{Fe}, \mathrm{Li}, \mathrm{Mg}, \mathrm{Mn}, \mathrm{Mo}, \mathrm{Ni}, \mathrm{Pb}, \mathrm{Sb}, \mathrm{Se}, \mathrm{Sr}, \mathrm{Ti}, \mathrm{Tl}, \mathrm{V}, \mathrm{Zn}$, $100 \mathrm{mg} \mathrm{L}^{-1}$ each, Merck) and sodium and copper standard solutions (for chemical analysis, Kanto Chemical) were used. The other reagents used for this study were of guaranteed or analytical reagent grade.

\section{Procedures}

Preparation of CM-PAA resin. A porous methacrylate resin, which was prepared and sieved according to procedures described in a previous report, ${ }^{29}$ was used in this study.

For the immobilization of PAA on the methacrylate resin, $5 \mathrm{~g}$ of the methacrylate resin was taken, and $5 \mathrm{~mL}$ of 2-propanol, and a mixture of PAA and deionized water was then added. These amounts are summarized in Table 1. The suspension was heated at $60{ }^{\circ} \mathrm{C}$ for $20 \mathrm{~h}$ with stirring at $200 \mathrm{rpm}$. After that, the suspension was filtered, and then the obtained resin was washed with deionized water and methanol in that order.

For the carboxymethylation of amino group in PAA on the resin, $1 \mathrm{~g}$ of the resin immobilizing PAA was taken, and then $10 \mathrm{~mL}$ of $1 \mathrm{~mol} \mathrm{~L}^{-1}$ sodium hydroxide solution containing
Table 1 Conditions for the preparation of PAA resin and CMPAA resin, and CM rate of CM-PAA resin

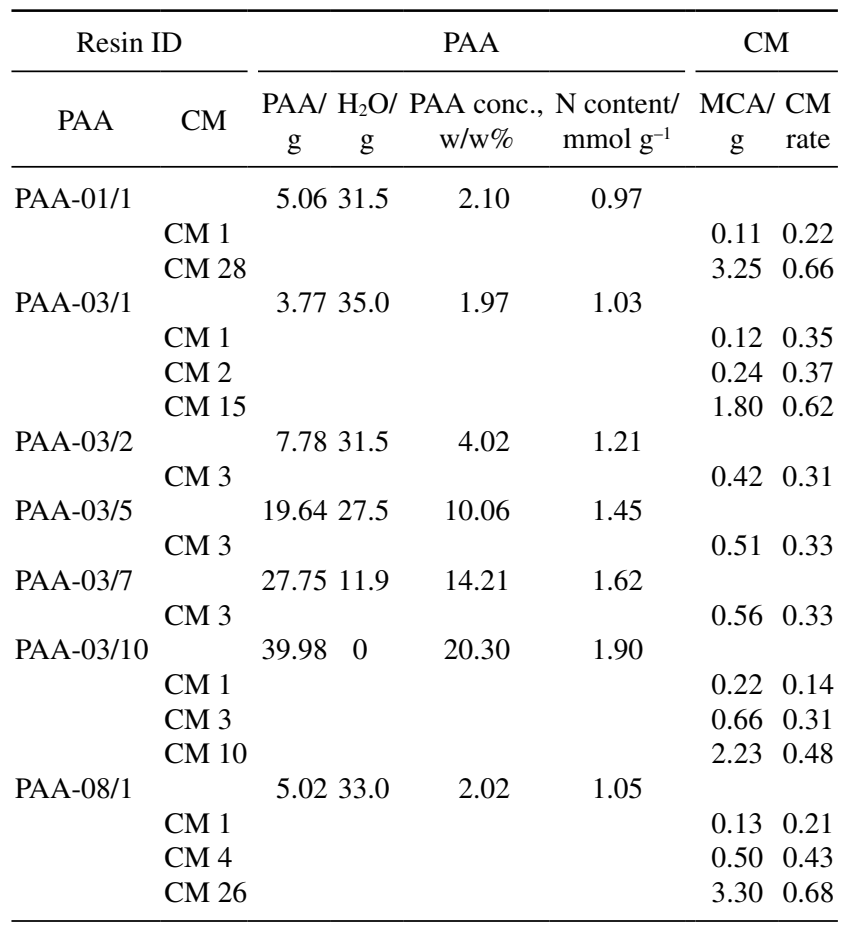

various amounts of MCA were added; the amounts are appended in Table 1. The suspension was shaken at $80 \mathrm{rpm}$ for $6 \mathrm{~h}$ at $50{ }^{\circ} \mathrm{C}$. After the filtration, the resin was washed with deionized water. The resin was then washed in $150 \mathrm{~mL}$ of $3 \mathrm{~mol} \mathrm{~L}^{-1}$ nitric acid under ultrasonic irradiation. The resin was filtered, and it was then washed with deionized water and methanol. The estimated structures of PAA resin and CM-PAA resin are shown in Fig. 1.

The carboxymethylation (CM) rate was determined based on the ratio of the ion exchange capacity for sodium ion to the amount of nitrogen on the resin..$^{29}$ The extraction capacity for $\mathrm{Cu}(\mathrm{II})$ was also investigated according to the previous report. ${ }^{29,32}$ Solid-phase extraction of trace elements. The solid-phase extraction behavior of each resin was investigated using a deionized water-based test solution, which was prepared by adding $10 \mu \mathrm{g}$ of each element and $5 \mathrm{~mL}-50 \mathrm{~mL}$ of $0.1 \mathrm{~mol} \mathrm{~L}^{-1}$ ammonium acetate solution to $100 \mathrm{~mL}-1000 \mathrm{~mL}$ of deionized water and then adjusting the solution $\mathrm{pH}$ using nitric acid and/or aqueous ammonia.

The PAA resin and CM-PAA resin $(0.25 \mathrm{~g})$ were packed into a 6-mL cartridge for solid-phase extraction (GL Sciences). The resin was conditioned using $5 \mathrm{~mL}$ of methanol, $3 \mathrm{~mol} \mathrm{~L}^{-1}$ nitric acid, $20 \mathrm{~mL}$ of deionized water, and $10 \mathrm{~mL}$ of $0.1 \mathrm{~mol} \mathrm{~L}^{-1}$ ammonium acetate solution in that order. Then the test solution was passed through the cartridge at various flow rates. After the cartridge was washed with $20 \mathrm{~mL}$ of deionized water, the extracted elements were eluted using $3 \mathrm{~mL}$ of $3 \mathrm{~mol} \mathrm{~L}^{-1}$ nitric acid; the solution was diluted to $10 \mathrm{~mL}$. The elements in the solution were determined using ICP-AES. An artificial seawater-based test solution, prepared according to the procedure described in a previous report, ${ }^{5,29,32,33}$ was also used for investigating the effect of coexisting ions.

A certified reference material, EnviroMAT Waste Water (EU-L-1, SCP Science), was used for evaluating the applicability of CM-PAA resin to separation and preconcentration of trace elements in water samples. The solid-phase extraction of trace elements in ground water, which was sampled at Toyama City in 


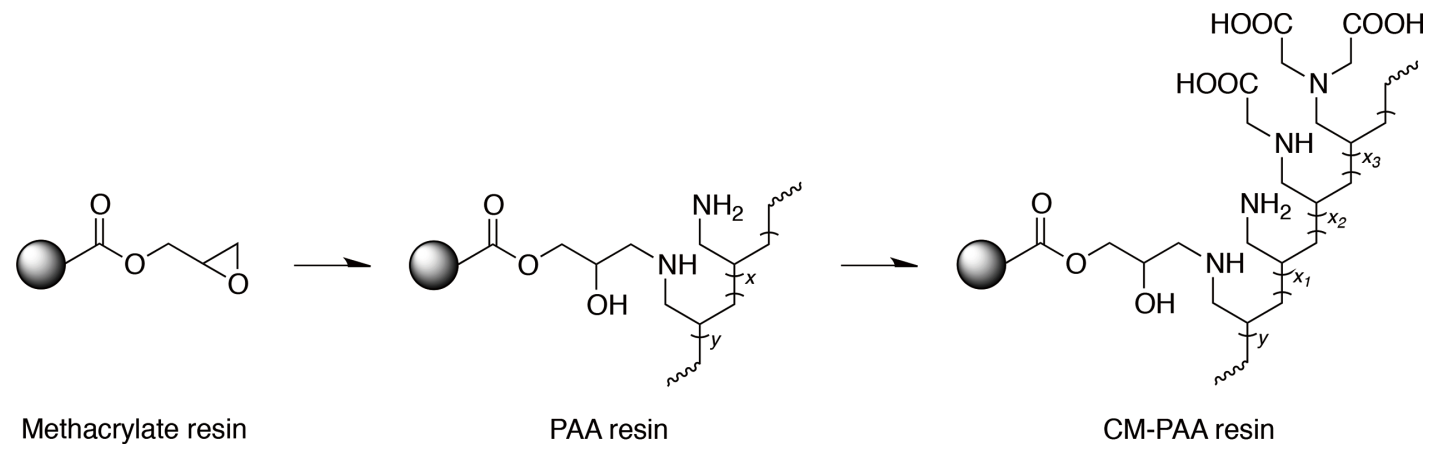

Fig. 1 Estimated structures of PAA resin and CM-PAA resin.

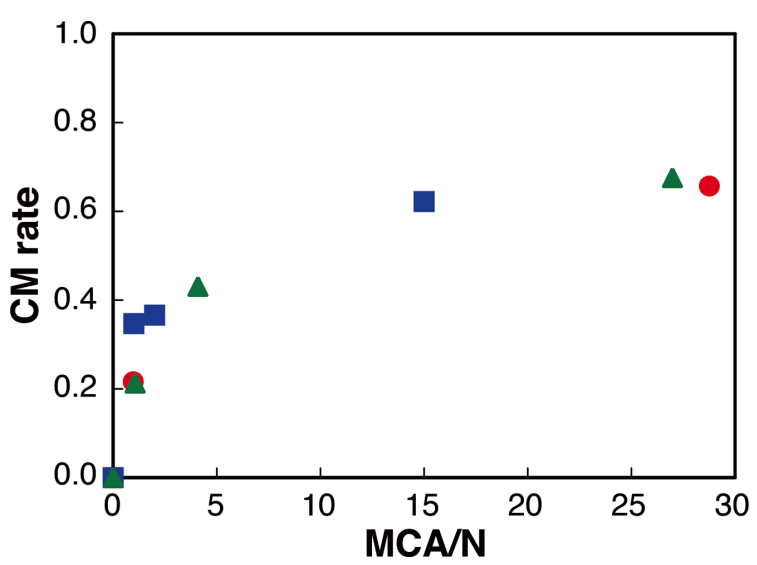

Fig. 2 Relationship between the ratio of the amount of MCA (mmol) to the nitrogen amount in the PAA-01 (-), PAA-03 ( $\square)$, or PAA-08 $(\triangle)$ resin used in the carboxymethylation step.

Toyama Prefecture, was also conducted; the sample solution was filtered through a membrane filter $(0.45 \mu \mathrm{m}$ of pore size, Omnipore membrane, Merck) and then the $\mathrm{pH}$ adjusted to 1 using nitric acid. Before use, $5 \mathrm{~mL}$ or $15 \mathrm{~mL}$ of $0.1 \mathrm{~mol} \mathrm{~L}^{-1}$ ammonium acetate solution was added to $100 \mathrm{~mL}$ or $300 \mathrm{~mL}$ of the solutions and the solution $\mathrm{pH}$ was adjusted to 5.5 or 7.0 using aqueous ammonia. The solid-phase extraction was conducted in the same way described above; the flow rate of the sample

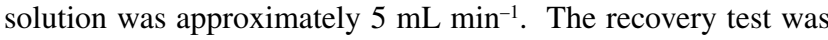
also conducted using a solution spiked with each element.

\section{Results and Discussion}

Preparation of PAA resin and CM-PAA resin

The effect of molecular weight of PAA used for the preparation of PAA resin were investigated. The results are shown in Table 1. The nitrogen contents in the resins immobilizing PAAs having different molecular weights (PAA-01/1, PAA-03/1, and PAA-08/1) were almost constant when the solutions containing approximately $2 \mathrm{w} / \mathrm{w} \%$ of PAAs were used in the PAA immobilization step. These results indicate that the molecular weight of PAA barely affected the nitrogen contents in the PAA resins when the same concentration of PAA is applied in the PAA immobilization step. This is because PAA is a regular macromolecule, which contains primary amine in the repeating units. The relationship between the ratio of the amount of MCA to the nitrogen content of PAA resin used in the carboxy-

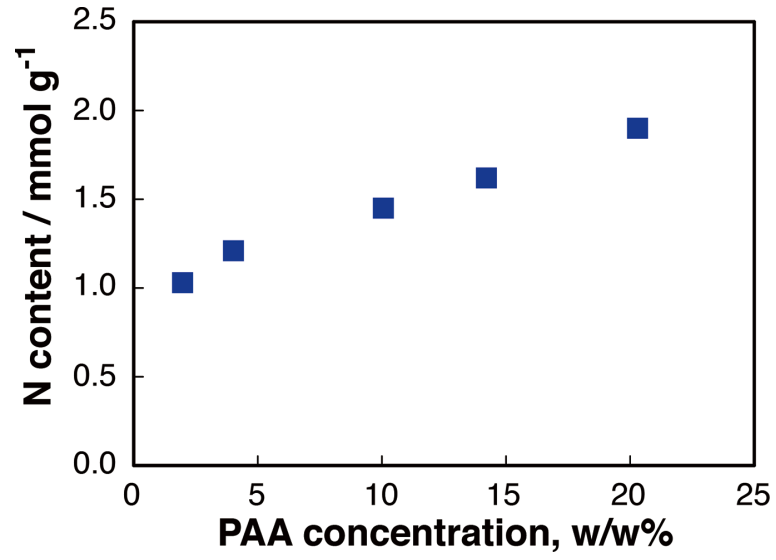

Fig. 3 Relationship between the PAA-03 concentration in the preparation of PAA-03 resin and the nitrogen content in PAA-03 resin.

methylation step and the CM rate is shown in Fig. 2. When the amino groups in the PEI immobilized on the resin were carboxymethylated, the $\mathrm{CM}$ rate was affected by the molecular weight of PEI. ${ }^{29}$ In the case of the PAA resin, however, the CM rate increased with an increase in the ratio of MCA to the nitrogen content, and reached almost constant (approximately 0.65 ) without any influence by the molecular weight of PAA. This seems to be also due to the presence of only primary amine in the repeating unit of PAA; PAA would also be immobilized on the resin through the plural amino groups in the PAA. Since the molecular weight of PAA barely affected the preparation of PAA resin, PAA-03 was used for further study because of its highest concentration in the commercially available solution.

Then the effect of the concentration of PAA- 03 was investigated. As shown in Fig. 3, the nitrogen content in PAA resin proportionally increased when increasing the concentration of PAA in the aqueous solution in the PAA immobilization step. From these results, it can be seen that the high concentration of PAA solution is preferable to prepare PAA, resin which has high nitrogen content. The nitrogen content was almost constant for at least $10 \mathrm{~h}$ of the immobilization time at $50{ }^{\circ} \mathrm{C}$. As shown in the results for CM-PAA resins (Table 1), the CM rate increased when increasing the ratio of the amount of MCA to the nitrogen content.

Solid-phase extraction behavior of trace elements

The chelating properties of PAA and CM-PAA have been studied; ${ }^{34,35}$ a chelating fiber containing CM-PAA has also been 


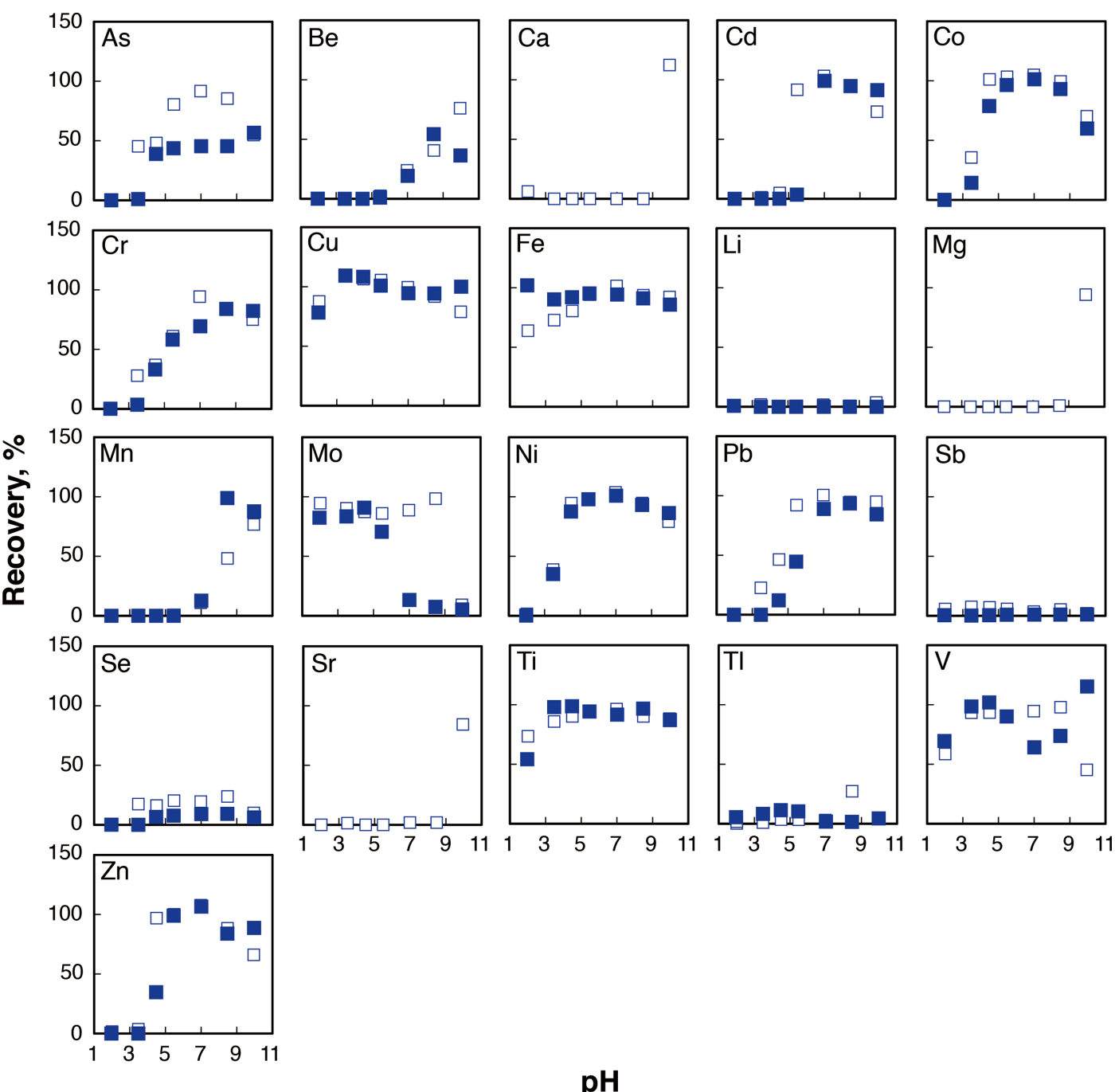

Fig. 4 Effect of $\mathrm{pH}$ on the recoveries of 21 elements using CM3-PAA-03/10 resin. Extraction: Solution volume, $100 \mathrm{~mL}$; each element, $10 \mu \mathrm{g}$; flow rate, $3 \mathrm{~mL} \mathrm{~min}^{-1}$. Elution: $3 \mathrm{~mol} \mathrm{~L}^{-1} \mathrm{HNO}_{3}$, $3 \mathrm{~mL}$; final volume, $10 \mathrm{~mL}$. $\square$ ) Deionized water-based test solution. $\square$ ) Artificial seawater-based test solution.

developed. ${ }^{36}$ In this study, the effect of $\mathrm{pH}$ on the recoveries of 21 elements was investigated using PAA resin and CM-PAA resin. At first, PAA-01/1, PAA-03/1, and PAA-08/1 resins and their carboxymethylated ones were compared; the results are shown in Figs. S1 - S3 in Supporting Information. The solidphase extraction behavior using PAA resin was similar to that using PEI resin; however, the recoveries of many elements, including $\mathrm{Cd}, \mathrm{Co}, \mathrm{Cu}, \mathrm{Fe}, \mathrm{Mn}, \mathrm{Ni}, \mathrm{Pb}$, and $\mathrm{Zn}$, were lower than in the case of using the PEI resin. ${ }^{29}$ This is because the nitrogen content in PAA resins was less than in PEI resin. ${ }^{29}$ The extraction ability increased when increasing the $\mathrm{CM}$ rate. The recoveries of some elements, such as $\mathrm{Cu}$, were improved in the acidic region; however, the recovery of Mo decreased in the weakly alkaline region. Ca was scarcely recovered at $\mathrm{pH} 7$ and below when a resin with up to a $\mathrm{CM}$ rate of 0.5 was used; however, the resin having a rate of 0.6 or higher tended to extract $\mathrm{Ca}$ even at $\mathrm{pH}$ around 5. These tendencies were similar to that for CM-PEI resin. ${ }^{29}$ From these results, it can be seen that the solid-phase extraction behavior was scarcely influenced by the molecular weight of PAA immobilized on the resin.

Then, PAA-03/1 - PAA-03/10 resins and their carboxymethylated ones having a $\mathrm{CM}$ rate of around 0.3 were compared.
As shown in Fig. 4 and Figs. S4 - S7 in Supporting Information, the solid-phase extraction behavior was scarcely affected by the nitrogen content. The improvement of the extraction ability with the increase of the $\mathrm{CM}$ rate was significant when the nitrogen contents were higher. On the other hand, CMPAA-03/10 resin having a CM rate of 0.48 recovered $\mathrm{Ca}$ even at $\mathrm{pH}$ around 4. From these results, it is preferable to use CM3PAA-03/10 resin, which has a CM rate of 0.31 , for the solidphase extraction of trace elements. The extraction capacity of CM3-PAA-03/10 resin for $\mathrm{Cu}$ (II) was $0.24 \mathrm{mmol} \mathrm{g}^{-1}$. The solid-phase extraction behavior for some elements using CM3PAA-03/10 resin was similar to those using some commercially available resins, such as NOBIAS Chelate PA-1, InertSep ME-2, and Presep PolyChelate. However, the recoveries of some elements under acidic conditions using CM3-PAA-03/10 resin were lower than for those using the commercially available ones.

Some conditions for the solid-phase extraction of 10 elements, namely $\mathrm{Cd}, \mathrm{Co}, \mathrm{Cu}, \mathrm{Fe}, \mathrm{Mo}, \mathrm{Ni}, \mathrm{Pb}, \mathrm{Ti}, \mathrm{V}$, and $\mathrm{Zn}$, which were quantitatively recovered using CM3-PAA-03/10 resin, were then investigated using a deionized water-based test solution. Figure S8 in Supporting Information shows the results for the 


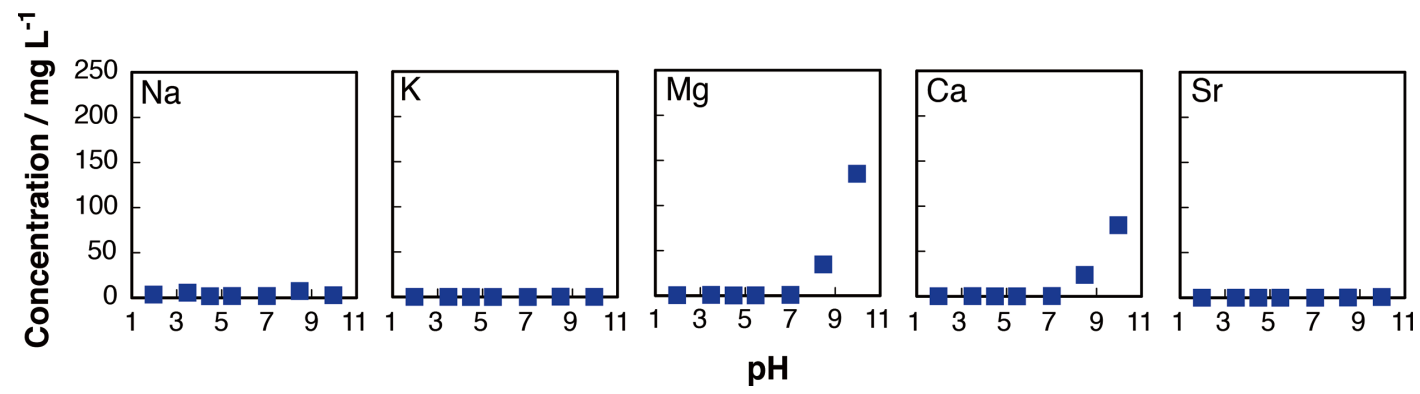

Fig. 5 Effect of $\mathrm{pH}$ on the solid-phase extraction of $\mathrm{Na}, \mathrm{K}, \mathrm{Mg}, \mathrm{Ca}$, and $\mathrm{Sr}$ in the artificial seawaterbased test solution using CM3-PAA-03/10 resin. Extraction: Solution volume, $100 \mathrm{~mL}$; each element, $10 \mu \mathrm{g}$; flow rate, $3 \mathrm{~mL} \mathrm{~min}{ }^{-1}$. Elution: $3 \mathrm{~mol} \mathrm{~L}^{-1} \mathrm{HNO}_{3}, 3 \mathrm{~mL}$; final volume, $10 \mathrm{~mL}$. The concentrations in the final solution are shown.

effect of flow rate on the recoveries of trace elements. Although the recoveries of $\mathrm{Cd}, \mathrm{Pb}$, and $\mathrm{Zn}$ slightly decreased with increasing flow rate, quantitative recoveries were obtained for the other elements up to approximately $40 \mathrm{~mL} \mathrm{~min}^{-1}$. The recoveries were also little affected by the solution volume in the range of $100 \mathrm{~mL}-1000 \mathrm{~mL}$.

The effect of major elements, such as alkali and alkaline earth elements, on the recoveries of the elements were also investigated using an artificial seawater-based test solution. As appended in Fig. 4, a slight influence was observed for $\mathrm{Cd}, \mathrm{Fe}, \mathrm{Pb}$, and $\mathrm{Zn}$. The recoveries of Mo and $\mathrm{V}$ also decreased under weakly alkaline conditions. On the other hand, the major ions, such as $\mathrm{Na}, \mathrm{K}, \mathrm{Mg}, \mathrm{Ca}$, and $\mathrm{Sr}$, were barely recovered at $\mathrm{pH} 7$ and below as shown in Fig. 5. The recoveries of $\mathrm{Cu}, \mathrm{Fe}$, and $\mathrm{Ti}$ were hardly affected even when the flow rate was increased; however, those of the other elements decreased with the increase of the flow rate (Fig. S8). From the results shown in Fig. 4, the recoveries seem to improve when increasing the solution $\mathrm{pH}$ in the solid-phase extraction. These results indicate that the solidphase extraction ability of CM3-PAA-03/10 resin was lower than that of CM-PEI resin. ${ }^{29}$ This seems to be due to the difference of nitrogen content in these resins. The ability of CM-PAA resin would be improved by increasing the nitrogen content; it could be achieved if the concentration of PAA can be increased in the PAA-immobilization step.

Application to analyses of certified reference material and real environmental water sample

CM3-PAA-03/10 resin was applied to the solid-phase extraction of the 10 elements described above in water samples. Before the application, the limit of detection (LOD) and the limit of quantification (LOQ) for each element using ICP-AES after the solid-phase extraction were calculated based on three times and ten times of the standard deviation of the blank value ( $n=8)$ using $500 \mathrm{~mL}$ of blank solutions, respectively. The LODs were $0.004 \mu \mathrm{g} \mathrm{L}^{-1}$ (for Co) $-0.22 \mu \mathrm{g} \mathrm{L}^{-1}$ (for $\mathrm{Zn}$ ); the blank values for all the elements were less than their LODs in ICP-AES (Table S3 in Supporting Information). The calibration curves were prepared using $100 \mathrm{~mL}$ of a solution; straight lines were obtained in the ranges from around LOQs to at least $10 \mu \mathrm{g}$ for all the elements.

Based on the results obtained above, the solid-phase extraction of the elements, except for $\mathrm{Ti}$, in a certified reference material, EU-L-1 Waste Water, was attempted. The results are summarized in Table 2. When the solid-phase extraction was conducted at $\mathrm{pH}$ 5.5, low values were obtained for $\mathrm{Cd}, \mathrm{Pb}$, and $\mathrm{Zn}$, and the large variations were observed for some elements. However, these were improved when the extraction was conducted at
Table 2 Results for determining some elements in certified reference material (EU-L ${ }^{-1}$, Waste Water)

\begin{tabular}{cccc}
\hline \multirow{2}{*}{ Element } & \multicolumn{2}{c}{${\text { Found } \mathrm{a} / \mathrm{mg} \mathrm{L}^{-1}}$} & $\begin{array}{c}\text { Consensus value/ } \\
\mathrm{mg} \mathrm{L}^{-1}\end{array}$ \\
\cline { 2 - 3 } & $\mathrm{pH} 5.5$ & $\mathrm{pH} 7.0$ & 0.06 \\
$\mathrm{Cd}$ & $0.017 \pm 0.003$ & $0.060 \pm 0.001$ & 0.20 \\
$\mathrm{Co}$ & $0.199 \pm 0.011$ & $0.211 \pm 0.005$ & 0.26 \\
$\mathrm{Cu}$ & $0.295 \pm 0.008$ & $0.272 \pm 0.011$ & 0.11 \\
$\mathrm{Fe}$ & $0.103 \pm 0.008$ & $0.109 \pm 0.002$ & 0.10 \\
$\mathrm{Mo}$ & $0.101 \pm 0.006$ & $0.102 \pm 0.002$ & 0.20 \\
$\mathrm{Ni}$ & $0.199 \pm 0.008$ & $0.212 \pm 0.004$ & 0.10 \\
$\mathrm{~Pb}$ & $0.044 \pm 0.005$ & $0.095 \pm 0.002$ & 0.12 \\
$\mathrm{~V}$ & $0.124 \pm 0.001$ & $0.118 \pm 0.005$ & 0.06 \\
$\mathrm{Zn}$ & $0.047 \pm 0.007$ & $0.050 \pm 0.001$ & \\
\hline
\end{tabular}

a. Mean \pm standard deviation $(n=3)$.

Table 3 Results for determining some elements in ground water (pH 7.0)

\begin{tabular}{ccc}
\hline Element & ${\text { Found } / \mu \mathrm{L} \mathrm{L}^{-1}}$ & Recovery $^{\mathrm{a}} \%$ \\
\hline $\mathrm{Cd}$ & N.D. & $95 \pm 9$ \\
$\mathrm{Co}$ & N.D. & $101 \pm 2$ \\
$\mathrm{Cu}$ & $2.8 \pm 0.1$ & $107 \pm 2$ \\
$\mathrm{Fe}$ & $0.89 \pm 0.32$ & $95 \pm 4$ \\
$\mathrm{Mo}$ & N.D. & $(1 \pm 0.2)$ \\
$\mathrm{Ni}$ & N.D. & $107 \pm 1$ \\
$\mathrm{~Pb}$ & N.D. & $93 \pm 9$ \\
$\mathrm{Ti}$ & N.D. & $93 \pm 3$ \\
$\mathrm{~V}$ & N.D. & $(12 \pm 1)$ \\
$\mathrm{Zn}$ & $3.6 \pm 0.6$ & $99 \pm 4$ \\
\hline
\end{tabular}

a. Mean \pm standard deviation $(n=3)$.

$\mathrm{pH}$ 7.0. The separation and preconcentration of the elements in ground water were also tried at $\mathrm{pH}$ 7.0. As shown in Table 3, $\mathrm{Cu}, \mathrm{Fe}$, and $\mathrm{Zn}$ could be determined. In the recovery test, although low recoveries were obtained for Mo and $\mathrm{V}$, more than $93 \%$ of the other elements were recovered.

\section{Conclusions}

We succeeded in preparing a chelating resin immobilizing CMPAA, which has the ability to separate and preconcentrate trace element selectively. The selectivity is comparable to that of the CM-PEI resin. The molecular weight barely affected the amount 
of PAA immobilized on the resin and the CM rate using various amounts of MCA. These results and the fact that PAA is a regular macromolecule containing a primary amino group in the repeating units would indicate that the preparation of CM-PAA resin, which has almost the same selectivity, is easy even when PAAs from the different manufacturer and/or with the different reagent lot are used. The prepared CM-PAA resin could be applied for the separation and preconcentration of 10 elements in some water samples. However, its ability in solid-phase extraction seems to be lower than that of CM-PEI resin. Further studies, including an investigation of the increase in the nitrogen content on the resin derived by increasing the concentration of PAA in the immobilization step, are in progress.

\section{Acknowledgements}

The authors are grateful to Dr. Yoshikazu Horino at University of Toyama for his helpful discussion regarding the nucleophilicity of the amino group in aliphatic amine. The authors also thanks Ms. Eri Koori for her kind support for elemental analysis.

\section{Supporting Information}

Additional information and data, including operating conditions for ICP-AES, effect of $\mathrm{pH}$ on the recoveries of 21 elements using PAA and CM-PAA resins, effect of flow rate on the recoveries of some elements using CM3-PAA-03/10 resin, and limit of detection and limit of quantification for each element with the solid-phase extraction using CM3-PAA-03/10 resin, are given as Supporting Information. This material is available free of charge on the Web at http://www.jsac.or.jp/analsci/.

\section{References}

1. S. Kagaya and Y. Inoue, Bunseki, 2016, 521.

2. H. Katsumata, Anal. Sci., 2019, 35, 1289.

3. M. He, L. Huang, B. Zhao, B. Chen, and B. Hu, Anal. Chim. Acta, 2017, 973, 1

4. S. Kagaya, M. Gemmei-Ide, and Y. Inoue, "Chelating Resins", in "Encyclopedia of Polymeric Nanomaterials", ed. S. Kobayashi and K. Müllen, 2014, Springer-Verlag, Berlin, 1.

5. S. Kagaya, Y. Saeki, D. Morishima, R. Shirota, T. Kajiwara, T. Kato, and M. Gemmei-Ide, Anal. Sci., 2013, 29, 1107.

6. G. Xing, M. R. Sardar, B. Lin, and J.-M. Lin, Talanta, 2019, 204, 50.

7. M. Tsujisaka, S. Takano, M. Murayama, and Y. Sohrin, Anal. Chim. Acta, 2019, 1091, 146.

8. I. Wysocka and E. Vassileva, Anal. Chim. Acta, 2018, 1000, 144.

9. T. Watanabe, Y. Saito-Kokubu, H. Murakami, and T. Iwatsuki, Limnology, 2018, 19, 21.

10. K. Liu, X. Gao, L. Li, C.-T. A. Chen, and Q. Xing, Chemosphere, 2018, 212, 429.

11. S. L. Jackson, J. Spence, D. J. Janssen, A. R. S. Ross, and
J. T. Cullen, J. Anal. At. Spectrom., 2018, 33, 304.

12. S. Takano, M. Tanimizu, T. Hirata, K.-C. Shin, Y. Fukami, K. Suzuki, and Y. Sohrin, Anal. Chim. Acta, 2017, 967, 1.

13. A. J. M. Lough, J. K. Klar, W. B. Homoky, S. A. ComerWarner, J. A. Milton, D. P. Connelly, R. H. James, and R. A. Mills, Geochim. Cosmochim. Acta, 2017, 202, 1.

14. S. Tiwari, N. Sharma, and R. Saxena, Anal. Sci., 2016, 32, 1321.

15. G. Giakisikli, P. Zachariadis, I. Kila, N. Teshima, and A. Anthemidis, Anal. Lett., 2016, 49, 929.

16. T. Minami, W. Konagaya, L. Zheng, S. Takano, M. Sasaki, R. Murata, Y. Nakaguchi, and Y. Sohrin, Anal. Chim. Acta, 2015, 854, 183.

17. Y. Sohrin, S. Urushihara, S. Nakatsuka, T. Kono, E. Higo, T. Minami, K. Norisuye, and S. Umetani, Anal. Chem., 2008, 80, 6267.

18. K. Yamamoto, H. Sakamoto, A. Yonetani, and T. Shirasaki, Nippon Kaisui Gakkaishi, 2007, 61, 260.

19. H. Sakamoto, K. Yamamoto, T. Shirasaki, and Y. Inoue, Bunseki Kagaku, 2006, 55, 133.

20. S. Kagaya, Y. Aoki, Y. Saeki, T. Goto, M. Ohki, I. Obata, M. Saito, R. Shirota, and M. Gemmei-Ide, Bull. Soc. Sea Water Sci., Jpn., 2017, 71, 282.

21. C. Schlosser, J. Karstensen, and E. M. S. Woodward, Deep Sea Res., Part I, 2019, 148, 132.

22. A. J. M. Lough, W. B. Homoky, D. P. Connelly, S. A. Comer-Warner, K. Nakamura, M. K. Abyaneh, B. Kaulich, and R. A. Mills, Chem. Geol., 2019, 511, 225.

23. M. Giraud, V. Garcon, D. de la Broise, S. L'Helguen, J. Sudre, and M. Boye, Sci. Total Environ., 2019, 693, 133491.

24. S. H. Little, C. Archer, A. Milne, C. Schlosser, E. P. Achterberg, M. C. Lohan, and D. Vance, Chem. Geol., 2018, 502, 29.

25. I. Rapp, C. Schlosser, D. Rusiecka, M. Gledhill, and E. P. Achterberg, Anal. Chim. Acta, 2017, 976, 1.

26. Y. Takaku, K. Ishizuka, A. Nagaoka, M. Minakawa, T. Morita, and K. Fujimoto, Bunseki Kagaku, 2016, 65, 399.

27. Y. Nakashima, Y. Inoue, T. Yamamoto, W. Kamichatani, S. Kagaya, and A. Yamamoto, Anal. Sci., 2012, 28, 1113.

28. S. Kagaya, E. Maeba, Y. Inoue, W. Kamichatani, T. Kajiwara, H. Yanai, M. Saito, and K. Tohda, Talanta, 2009, 79, 146.

29. S. Kagaya, T. Kajiwara, M. Gemmei-Ide, W. Kamichatani, and Y. Inoue, Talanta, 2016, 147, 342.

30. Y. Inoue, Bunseki Kagaku, 2015, 64, 811.

31. F. Brotzel, Y. C. Chu, and H. Mayr, J. Org. Chem., 2007, 72,3679 .

32. S. Kagaya, R. Ikeda, T. Kajiwara, M. Gemmei-Ide, and Y. Inoue, Anal. Sci., 2019, 35, 413.

33. S. Kagaya and T. Yoshimori, Anal. Methods, 2012, 4, 4378.

34. S. Kobayashi, M. Tokunoh, T. Saegusa, and F. Mashio, Macromolecules, 1985, 18, 2357.

35. K. Naka, Y. Tachiyama, K. Hagihara, Y. Tanaka, M. Yoshimoto, A. Ohki, and S. Maeda, Polym. Bull., 1995, 35, 659.

36. S. Kagaya, H. Miyazaki, Y. Inoue, T. Kato, H. Yanai, W. Kamichatani, T. Kajiwara, M. Saito, and K. Tohda, J. Hazard. Mater., 2012, 203-204, 370. 